\title{
Erratum to: Recombinant Human Angiopoietin-1 Ameliorates the Expressions of ZO-1, Occludin, VE-cadherin, and PKC $\alpha$ Signaling after Focal Cerebral Ischemia/Reperfusion in Rats
}

\author{
Hang Yu $\cdot$ Ping Wang $\cdot$ Ping An $\cdot$ Yixue Xue
}

Published online: 9 November 2011

(C) Springer Science+Business Media, LLC 2011

\section{Erratum to: J Mol Neurosci}

DOI 10.1007/s12031-011-9584-5

The original version of this article unfortunately contained a mistake. The name of the corresponding author should be changed to "Yixue Xue", which is shown above. In the second address of authors P. Wang, P. An, Y. Xue, the post code of Institute of Pathology and Pathophysiology should be changed to " 110001 " as follows.

The online version of the original article can be found at http://dx.doi. org/10.1007/s12031-011-9584-5.

H. Yu $\cdot$ P. Wang $\cdot$ P. An $\cdot$ Y. Xue $(\bowtie)$

Department of Neurobiology, College of Basic Medicine,

China Medical University,

Shenyang 110001, China

e-mail: xueyixue888@yahoo.com.cn

H. Yu

Department of Physiology,

Daqing Branch of Haerbin Medical University,

Daqing 163319, China

P. Wang • P. An · Y. Xue

Institute of Pathology and Pathophysiology,

China Medical University,

Shenyang 110001, China 